\title{
SERIAM OS DIREITOS DA PERSONALIDADE MERCADORIAS? REFLEXÕES SOBRE A EXISTÊNCIA DE UM MERCADO DE DIREITOS EXISTENCIAIS
}

\author{
WOULD THE PERSONALITY RIGHTS BE COMMODITIES? \\ REFLECTIONS ABOUT THE EXISTENCE OF A MARKET OF \\ EXISTENTIAL RIGHTS
}

\section{${ }^{1}$ Lucas Costa de Oliveira}

\section{RESUMO}

Compra-se: barriga de aluguel indiana, direito de ser imigrante nos Estados Unidos, óvulos e esperma de grife. Vende-se: espaço no corpo para publicidade comercial, serviço de cobaia humana em testes de laboratórios farmacêuticos, esterilização ou controle permanente de natalidade. Seriam os direitos da personalidade mercadorias? Pode-se levantar ao menos duas hipóteses para o problema posto: i) direitos existenciais devem ser deixados em uma esfera alheia ao mercado; ii) direitos existenciais devem ser abarcados pela esfera do mercado. Desse modo, o artigo pretende abordar tais questões sob a perspectiva de três pensadores que se detiveram sobre o tema: Stefano Rodotà, Michael Sandel e Zygmunt Bauman. O objetivo é construir, de maneira crítica, uma base teórica sólida para pensar a problemática proposta e então estabelecer algumas notas conclusivas sobre o assunto.

Palavras-chave: Direitos da personalidade, Direitos existenciais, Mercadorias, Mercado de direitos

\begin{abstract}
Available for purchase: Indian surrogacy, right to be an immigrant in the United States, chic ova and sperm. For sale: space in the body for commercial advertising, human guinea pig in service of pharmaceutical laboratory tests, sterilization or permanent birth control. Would the personality rights be commodities? It is possible to raise at least two hypotheses for the problem posed: i) existential rights should be left outside market sphere; ii) existential rights must be embraced by the market sphere. Thus, the article aims to address these issues from the perspective of three thinkers who were arrested on the subject: Stefano Rodotà, Michael Sandel and Zygmunt Bauman. The goal is to build, critically, a solid theoretical basis for thinking the problem proposal and then establish some concluding remarks on the subject.
\end{abstract}

Keywords: Personality rights, Existential rights, Commodities, Market of rights

\footnotetext{
${ }^{1}$ Mestrando em Direito Privado pela Pontifícia Universidade Católica de Minas Gerais - PUC, Minas Gerais, (Brasil) Email: tutortreinamento@gmail.com
} 


\section{INTRODUÇÃO}

Um imigrante ilegal nigeriano leva uma vida dura. Durante o dia dirige taxis clandestinos, à noite trabalha como recepcionista em um modesto hotel. Entre essas atividades ainda tem que fugir dos agentes da imigração, restando pouco (ou nenhum) tempo para dormir. Em situação semelhante se encontra uma exilada turca sem direito de trabalhar, mas que precisa de dinheiro para sobreviver em uma das cidades mais caras do mundo. Okwe (Chiwetel Ejiofor) e Senay (Audrey Tautou) são personagens apresentados em "Coisas bela e sujas" (Dirty Pretty Things), filme que retrata o submundo londrino repleto de drogas, prostituição, violência, corrupção, mas também repleto de luta, solidarismo, companheiris mo - coisas belas e sujas.

É nesse contexto que se desenrola a trama. Durante uma rotineira noite de trabalho, Okwe recebe uma ligação para vistoriar o quarto 510. Ao realizar tal tarefa, repara que o vaso sanitário se encontrava entupido e toma um choque ao saber o motivo do entupimento: um coração humano. O recepcionista pretende levar o caso para a polícia, contudo é aconselhado a não tomar tal medida, uma vez que sua situação é ilegal. Sua única confidente é Senay, que pouco pode fazer perante o caso. Com o desenrolar da história, Okwe descobre que há um funcionário do hotel envolvido com tráfico de órgãos. Os "doadores" cedem um rim e recebem um passaporte falsificado junto a um esquema para irem para outro país com uma nova identidade. As cirurgias são feitas de formas precárias, sem técnica, higiene e ambiente adequados. O resultado é quase sempre desastroso para uma das partes: morte ou graves infecções.

A ideia não é esgotar todas as nuances do filme, mas apenas trazer um pano de fundo para as reflexões que este artigo pretende abordar. Aspectos existenciais da vida humana, tutelados pelos direitos da personalidade, estariam fora do âmbito do mercado? Tais situações estariam sempre vinculadas a uma degradação do ser humano, a um ambiente obscuro, inadequado e corrupto?

Outras situações podem ser levantadas. Michael Sandel (2014) aponta algumas coisas que podem ser compradas atualmente: upgrade na cela carcerária, barriga de aluguel indiana, direito de ser imigrante nos Estados Unidos, óvulos e espermas "de grife”. Caso não haja dinheiro, o filósofo aponta algumas coisas que podem ser vendidas: um espaço no corpo para publicidade comercial, servir de cobaia humana em testes de laboratórios farmacêuticos, esterilização ou controle permanente de natalidade em casos de mães viciadas em drogas. 
Todos esses casos seriam passíveis do mesmo tratamento jurídico? Pode-se levantar ao menos duas hipóteses para os problemas postos: i) direitos existenciais devem ser deixados em uma esfera alheia ao mercado; ii) direitos existenciais devem ser abarcados pela esfera do mercado. Desse modo, o artigo pretende abordar tais questões sob a perspectiva de três pensadores que se detiveram sobre o tema: Stefano Rodotà (2010), Michael Sandel (2014) e Zygmunt Bauman (2008). O objetivo é construir, de maneira crítica, uma base teórica sólida para pensar a problemática proposta e então estabelecer algumas notas conclusivas sobre o assunto.

\section{DIREITOS DA PERSONALIDADE}

Faz-se necessário, em um momento inicial, estabelecer algumas breves considerações sobre os direitos da personalidade. Não se pretende esgotar o tema, mas apenas apontar aspectos que sejam indispensáveis ao desenvolvimento do artigo.

A primeira questão que surge é referente ao que se entende por direitos da personalidade. Assim, na definição de Maria de Fátima Freire de Sá e Bruno Torquato de Oliveira Naves (2011, p. 49), "[d]ireitos da personalidade são aqueles que têm por objeto os diversos aspectos da pessoa humana, caracterizando-a em sua individualidade e servindo de base para uma vida digna". Na mesma linha, Orlando Gomes (1992, p. 153), entende que "[...] são direitos considerados essenciais à pessoa humana, que a doutrina moderna preconiza e disciplina, a fim de resguardar a sua dignidade". Dessa maneira, entende-se que direitos da personalidade são aqueles que possibilitam e protegem o desenvolvimento da pessoa enquanto ser criativo, livre, digno. Através da construção desses direitos, estabelece-se uma esfera para cada ser humano se tornar a pessoa que escolha ser, através da sua própria concepção de vida boa, tornando-se apto para a construção da sua identidade e pessoalidade.

Pietro Perlingieri (2002) indica duas concepções sobre os direitos da personalidade. Uma reconhece um direito geral da personalidade, ao passo que a outra reconhece uma pluralidade de direitos da personalidade. A pluralidade pode consistir em uma série aberta de direitos (atipicidade), ou ainda consistir em uma série fechada de direitos (tipicidade). Conclui Perlingieri (2002, p. 156) no seguinte sentido: 
Não existe um número fechado de hipóteses tuteladas: tutelado é o valor da pessoa sem limites, salvo aqueles colocados no seu interesse e naqueles de outras pessoas. A elasticidade torna-se instrumento para realizar formas de proteção também atípicas, fundadas no interesse à existência e no livre exercício da vida de relações. Nenhuma previsão especial pode ser exaustiva e deixaria de fora algumas manifestações e exigências da pessoa que, mesmo como progredir da sociedade, exigem uma consideração positiva.

É nesse sentido que se fala que o elemento caracterizador dos direitos da personalidade é o seu conteúdo - e não sua forma.

Direitos da personalidade, direitos fundamentais, direitos humanos, direitos existenciais: existem diferenças entre esses termos? Ao estudar a diferença entre direitos da personalidade e direitos fundamentais, Brunello Stancioli (2010) analisa o critério formal e o critério da pertinência da norma. Pelo primeiro critério, direitos fundamentais seriam aqueles estabelecidos sobre a nomenclatura "direitos fundamentais", ao passo que direitos da personalidade seriam aqueles estabelecidos sobre a nomenclatura "direitos da personalidade". Trata-se de um critério formalista, que tenta estabelecer a distinção pela localização normativa dos direitos. Esse critério é apontado como inconsistente, na medida em que existem diversas disposições desses direitos espalhadas pelo ordenamento jurídico. Pelo segundo critério, os direitos fundamentais são entendidos como comandos para o legislador, enquanto os direitos da personalidade seriam comandos direcionados para a pessoa. Não obstante, sabe-se que os direitos fundamentais também se aplicam aos particulares (Drittwirking), na chamada eficácia horizontal. Robert Alexy (2012, p. 524) defende tese no mesmo sentido, ao dispor que "[...] as normas de direitos fundamentais também têm influência na relação cidadão/cidadão. Essa influência é especialmente clara no caso dos direitos em face da Justiça Civill". Assim, critério da pertinência da norma seria anacrônico e simplório.

A concepção estabelecida por Anderson Schreiber (2013, p. 13, grifo nosso) parece ser a correta:

A ampla variedade de termos não deve gerar confusões. Todas essas diferentes designações destinam-se a contemplar atributos da personalidade humana merecedores de proteção jurídica. O que muda é tão somente o plano em que a personalidade humana se manifesta. Assim, a expressão direitos humanos é mais utilizada no plano internacional, independentemente, portanto, do modo como cada Estado nacional regula a matéria. Direitos fundamentais, por sua vez, é o termo normalmente empregado para designar “direitos positivados numa constituição de um determinado Estado". É, por isso mesmo, a terminologia que tem sido preferida para tratar da proteção da pes soa humana no campo do direito público, em face da atuação do poder estatal. Já a expressão direitos da personalidade é empregada na alusão aos atributos humanos que exigemespecial proteção no campo das relações privadas, ou seja, na interação entre particulares, sem embargo de encontrarem também fundamento constitucional e proteção nos planos nacional e internacional. Trata-se, como se vê, do mesmíssimo fenômeno encarado por facetas variadas. O valor tutelado é idêntico e unitário: a dignidade humana. 
Direitos existenciais, por sua vez, é apontado em contraponto aos direitos patrimoniais. Esses seriam aqueles que se traduzem em uma expressão pecuniária, ao passo que aqueles não teriam um valor monetário. É nessa perspectiva que Pietro Perlingieri (2002) divide seu estudo entre situações jurídicas existenciais e situações jurídicas patrimoniais.

Assim sendo, apesar de entender que existem distinções pontuais entre os termos indicados, adotar-se-á, nos limites desse artigo, a posição que tais termos são superpostos. Trata-se, portanto, de um critério teleológico, na medida em que todos têm uma finalidade comum: a proteção da dignidade humana.

Um último ponto merece atenção. Os direitos da personalidade são apontados como absolutos, necessários, vitalícios, intransmissíveis, irrenunciáveis, extrapatrimoniais, imprescritíveis e impenhoráveis. Dentre essas características, duas se destacam para o estudo do tema proposto: a intransmissibilidade e a extrapatrimonialidade. Caio Mário da Silva Pereira (2007, p. 242) entende que são intransmissíveis "[...] porque o indivíduo goza de seus atributos, sendo inválida toda tentativa de sua cessão a outrem, por ato gratuito como oneroso". A extrapatrimonialidade dispõe que "[a]pesar de os direitos da personalidade poderem produzir consequências econômicas, eles não são passíveis de aferição ou avaliação quantitativa nesta esfera" (SÁ; NAVES, 2011, p. 64).

A caracterização de um mercado de direitos da personalidade perpassa pela desconstrução ou relativização dessas duas características, o que será possível (ou não) apenas no desenvolvimento deste artigo.

\section{O MERCADO DOS DIREITOS}

O jurista italiano Stefano Rodotà evidencia o surgimento de um mercado dos direitos em seu livro "La vida y las reglas: entre el derecho y el no derecho". O mercado dos direitos seria aquele "[...] em que os tradicionais direitos econômicos, inscritos na liberdade de comércio, se mesclam com direitos fundamentais que, alheios à lógica de intercâmbio, buscam também uma infinita possibilidade de expansão"" (RODOTÀ, 2010, p. 74, tradução nossa).

\footnotetext{
${ }^{1}$ [...] en el que los tradicionales derechos económicos, inscritos en la libertad de comercio, se mezclan con derechos fundamentales que, ajenos a la lógica del intercambio, buscan también una infinita possibilidad de expansión.
} 
Existe ainda, completando a lógica mercantil instaurada no Direito, o turismo de direitos, em que as pessoas podem escolher qual ordenamento recairá sob suas condutas - uma espécie de direito à la carte. É o caso do turismo abortivo, em que pessoas viajam para países em que a prática é permitida, bem como o turismo da morte, em que pessoas viajam para países com legislações permissivas para a prática da eutanásia e suicídio assistido. É esse o caso da Suíça. A legislação permite a interpretação favorável à prática do suicídio assistido, na medida em que prevê que apenas cometem crime aqueles que auxiliem "por motivos egoístas" o suicídio de alguém. Se quem auxilia não puder ser acusado de uma motivação egoística, não será punido. Nessa perspectiva, edificaramse diversas clínicas para o auxilio ao suicídio nesse país, como o caso da Dignitas, Exit e Ex International. A Swissinfo (2014) aponta que cerca de 1800 pessoas se suicidaram em 2007 na Suíça, sendo que 400 foram assistidas nessa decisão por tais organizações. Ainda, aponta que a absoluta maioria (85\%) das 141 pessoas que a Dignitas assistiu no ano de 2007, vieram do exterior. Para estrangeiros, o custo total de um suicídio assistido, incluindo serviço médico e cremação, seria de cerca de sete mil euros.

Situação semelhante e que vem ganhando espaço é o turismo reprodutivo. Cada vez mais nota-se uma crescente mobilidade mundial por parte daquelas pessoas que, alcançadas pelas restrições legais dos seus países de origem, ultrapassam fronteiras na busca pelo exercício da sua liberdade procriativa. Em dezembro de 2010, o Wall Street Journal publicou reportagem dando publicidade ao planethospital.com, uma empresa situada na Califórnia que oferece serviços de intermediação de práticas médicas nos mais diversos países do globo. Dentre tais práticas, encontram-se as possibilidades da reprodução humana assistida. O mesmo jornal relatou o caso de um casal italiano que, mediante a utilização do espermatozoide do marido conjugado com o óvulo de uma doadora europeia anônima, estava na espera do nascimento do filho na ilha grega de Creta, eis que uma búlgara, "mãe de aluguel", estaria em vias de dar a luz (SÁ; MOUREIRA, 2015).

Stefano Rodotà critica justamente essa mercantilização do direito, a submissão do direito ao mercado. Frente a esse cenário, a pergunta que se coloca é: seria possível a mercantilização dos direitos da personalidade com fundamento no exercício de autonomia da vontade? José Luis Piñar Mañas (2010, p. 15-16, tradução nossa) esclarece a posição do jurista italiano: 
Seria radicalmente contraditório com a centralidade da liberdade e da dignidade, que superam qualquer perspectiva patrimonial da pessoa. São inegociáveis, estão fora do mercado. A resposta há de ser, portanto, negativa. A dignidade, a liberdade, os direitos fundamentais são inderrogáveis, formam parte do "indecidível", daquilo que não se pode decidir. [...]. Os direitos são indisponíveis inclusive para seus titulares. ${ }^{2}$

A grande questão seria, portanto, que o estabelecimento de um mercado de direitos da personalidade seria um caminhar em sentido contrário à dignidade e à liberdade do ser humano, devendo permanecer na esfera do inegociável. Aqui caberia uma intervenção: um mercado de direitos existenciais não poderia, em hipótese alguma, ser uma afirmação e um exercício de dignidade, autonomia e liberdade? Uma mulher que comercializa sua capacidade reprodutiva para obter renda para cuidar de sua própria família ou um homem que aceita uma remuneração para servir de cobaia em testes farmacêuticos para conseguir pagar sua moradia, estariam agindo de maneira condenável e ilegal?

O próprio Rodotà (2010, p. 49-50, tradução nossa) estabelece algumas ponderações:

Contudo, estamos frente à máxima garantia ou frente à máxima expropriação? Ao tornarse "insaciáveis", os direitos fundamentais retiram das pessoas a possibilidade de modificar o ambiente jurídico em que vivem, impedem toda intervenção da política e, com isso, acabam imperando definitivamente sobre a vida. ${ }^{3}$

Nesse sentido, entende que essa maneira de interpretar tais direitos pode também ser violenta, afinal a legislação nem sempre representa uma maior plenitude da vida, podendo também significar a sua completa anulação. Por outro lado, a ausência do direito não representa por si só uma maior liberdade e autonomia. Pelo contrário, o espaço de não direito é condicionado por um unilateralismo religioso, ideológico ou econômico. Acontece que um espaço dominado pelo mercado e suas regras não é democrático, podendo levar a situações de injustiça e inequidade afinal, aqueles que têm o poder de desfrutar do mercado, são aqueles (e somente aqueles) que têm o poder de pagar.

Tais considerações não significam que não possa haver mudanças profundas na estrutura dos direitos fundamentais, inclusive chegar à sua negação. Não obstante, essa mudança representaria uma mutação paradigmática, de um modelo de sociedade para outro. Isso ocorre em

\footnotetext{
2 Sería radicalmente contradict orio com la centralidad de la libertad y la dignidad, que superan cualquier perspectiva patrimonial de la persona. Son innegociables, están fuera del mercado. La respuesta há de ser por tanto claramente negativa. La dignidad, la libertad, los derechos fudamentales son inderogables, forman parte de lo "indecidible", de aquello sobre lo que no puede decidirse. [...]. Los derechos son indisponibles incluso para sus titulares.

3 Pero ¿estamos ante la máxima garantía o ante la máxima expropiación? Al volverse “insaciables”, los derechos fundamentaleslequitanalas personas la posibilidad de modificar el ambiente jurídico en el que viven, impiden toda intervención de la política y, con ello, acaban imperando definitivamente sobre la vida
} 
razão do jurista italiano considerar que os direitos fundamentais não representam apenas direitos individuais, mas também o fundamento político-institucional da sociedade. Nessa medida, estão fora de negociação tanto pelos indivíduos, quanto pelo Estado.

Em suma, Stefano Rodotà entende que direitos da personalidade devem permanecer fora da esfera de mercado, pois a mercantilização de tais direitos seria uma afronta à liberdade e à dignidade das pessoas - e nada pode justificar uma existência sem liberdade e dignidade.

\section{O LIMITE MORAL DO MERCADO}

Michael J. Sandel, filósofo americano e professor da Universidade de Harvard, aborda a questão dos limites morais do mercado em uma perspectiva casuística. Através da análise de diversas situações infiltradas pela comercialização, busca encontrar um limite para a penetração do mercado nas esferas existenciais da vida humana. Dentre os diversos casos analisados no livro " $\mathrm{O}$ que o dinheiro não compra: os limites morais do mercado", três foram escolhidos para uma análise mais detida.

Existe um grande número de bebês que são gerados por mães viciadas em drogas, sem condições financeiras e emocionais para cuidarem dos seus filhos. O resultado dessa prática é desolador: crianças que já nascem viciadas, que sofrerão abusos, ou então serão abandonadas. Tendo tal horizonte em mente, Barbara Harris, fundadora da organização caritativa Project Prevention, sitiada nos Estados Unidos, pensou em uma solução para o problema. As mães viciadas que aceitam serem esterilizadas ou se submetem permanentemente a um controle de natalidade, são remuneradas em US\$ 300. Harris também levou seu programa para a Grã-Bretanha, onde sofreu muita resistência da imprensa e da Associação Médica Britânica. No Quênia, a proposta consiste no pagamento de US\$ 40 para mulheres portadoras do vírus HIV que aceitem dispositivos intrauterinos de contracepção.

Barbara Harris reconhece que quase sempre as clientes utilizam o dinheiro para comprar drogas, contudo entende que é um preço justo para impedir que crianças venham a nascer sem nenhuma perspectiva. Do ponto de vista mercadológico a transação gera benefícios para ambas as partes, não havendo nenhum problema. A viciada, no exercício de sua autonomia, recebe sua remuneração, ao passo que a organização recebe a garantia de que não haverá mais filhos gerados 
pela mãe viciada. Trata-se, portanto, de uma troca eficiente: fornece o bem à pessoa que se dispõe a pagar mais por ele.

Todavia, do ponto de vista moral, a esterilização destas mulheres vem sofrendo rejeições. Os argumentos são de dois tipo: a coerção e o suborno. Pelo primeiro, fala-se que as mães viciadas que aceitam a remuneração para serem esterilizadas não agem livremente. Em virtude da situação econômica dessas mulheres, haveria uma coerção irresistível. O segundo argumento diz respeito ao que está sendo comprado e vendido. O suborno ou corrupção consiste em comprar e vender algo que não deveria estar submetido ao mercado.

Sandel também analisa um clássico estudo sobre a doação de sangue realizado pelo sociólogo britânico Richard Titmuss. Nesse estudo, Titmuss compara o sistema de doação de sangue em vigor no Reino Unido, onde é realizado por voluntários não remunerados, bem como o sistema de doação de sangue dos Estados Unidos, onde em parte é realizado por voluntários não remunerados e outra parte é comprada, em geral da população de baixa renda. O sociólogo aponta que em termos econômicos e práticos, o sistema do Reino Unido funciona melhor do que o dos Estados Unidos, onde há escassez crônica, desperdício de sangue, custos mais altos e maior risco de contaminação.

Além do argumento pragmático, Richard Titmuss aponta dois argumentos de ordem moral. O primeiro diz respeito à exploração dos pobres, uma vez que a doação é feita em grande parte por pessoas de baixa renda, incapacitadas, desempregadas, negras, levando ao surgimento de uma nova classe de explorados. Não obstante esse argumento cabe a indagação: sem a remuneração para a doação de sangue esse grupo de pessoas deixa de ser explorado? $\mathrm{O}$ segundo argumento entende que a transmutação do sangue em mercadoria acaba com o sentimento de obrigação em doar sangue, diminuindo o espírito altruísta e a relação de doação.

A publicidade vem ocupando espaços cada vez mais inusitados nos últimos tempos. Agora o próprio corpo pode ser transformado em um outdoor. Em 1988 um pequeno restaurante mexicano fez a oferta de almoço livre pelo resto da vida para quem tatuasse o logotipo do restaurante no corpo - um garoto de sombreiro cavalgando uma gigantesca espiga de milho. Em poucos meses, mais de quarenta pessoas andavam por São Francisco com a tatuagem no corpo. Em Londres uma empresa começou a comercializar espaço publicitário na testa das pessoas. As tatuagens eram temporárias e foram recrutados estudantes universitários dispostos a andar com os logotipos na testas pela remuneração de $£ 4,20$ por hora. Na mesma linha, Air New Zealand contratou trinta 
pessoas para rasparem a cabeça e usarem uma tatuagem temporária na parte de trás com a frase: "Precisando mudar? Viaje para Nova Zelândia". A remuneração era de US\$ 777 - em alusão ao Boeing 777. Por fim, Michael Sandel relata o caso de uma mulher que leiloou o acesso comercial à sua própria testa, com o objetivo de arrecadar fundos para a educação do seu filho. Um cassino online aceitou pagar o preço de US\$ 10.000 e Kari Smith teve o endereço eletrônico do cassino tatuado na testa.

Tendo analisado esses e outros casos, o filosofo americano sintetiza duas objeções que reverberaram no debate a respeito do que o dinheiro deve ou não comprar. A objeção da equanimidade diz respeito às situações de desigualdade que as escolhas de mercado podem gerar, ao passo que a objeção da corrupção aponta para as atitudes e normas que podem ser prejudicadas, alteradas e dissolvidas pelo mercado.

Elucidativo é o exemplo de Michael Sandel (2014, p. 110):

É verdade que o dinheiro pode comprar um rim sem comprometer seu valor. Mas será que os rins devem ser comprados e vendidos? Os que achamque não costumamlevantar dois argumentos: afirmam que esses mercados exploram os pobres, cuja decisão de vender o rim pode não ser realmente voluntária (o argumento da equanimidade). Ou então sustentam que esses mercados promovem uma visão degradante e coisificante da pessoa humana, como se fosse uma coleção de partes avulsas (o argumento da corrupção).

Destarte, a objeção da equanimidade é pautada em um vício de consentimento, em sentido amplo. Esse argumento aponta para as consequências da mercantilização de todos os aspectos existência humana, aproximando-se, portanto, de um argumento utilitarista. Assim sendo, em uma situação ideal, onde todos pudessem consentir de maneira efetivamente livre, sem nenhum tipo de coerção, a prática comercial não sofreria objeção. Qualquer coisa poderia ser comprada e vendida. Por outro lado, a objeção da corrupção indica um defeito intrínseco, apontando para um argumento categórico. Dessa maneira, vender coisas de caráter existencial e fundamental seria degradante por si só.

O contra-argumento a essas objeções é baseado no princípio de que o mercado não altera o caráter dos bens trocados, nem mesmo diminuem seu valor. Assim, o único ponto a ser analisado deve ser a relação custo benefício para ambas as partes. Negociar um rim ou um carro não mudaria o modo como se enxerga tais coisas.

Um outro ponto levantado, argumenta no sentido que o comportamento ético é uma mercadoria que precisa ser economizada, uma vez ser um bem escasso. Explica-se: ao se atribuir 
valor econômico a ações, guarda-se o altruísmo, a generosidade, a solidariedade para momentos em que sejam realmente necessários. São virtudes escassas e que se perdem ao serem utilizadas. Assim, se alguém é pago para doar sangue, poderá usar de sua solidariedade em outros momentos mais oportunos. A controvérsia surge pois a virtude, tal como proposta por Aristóteles, não é um bem que se finda pelo uso, mas se fortalece com o exercício. Não se nasce virtuoso, torna-se.

O que Michael Sandel (2014, p.16) propõe como conclusão é que

[...] algumas coisas da vida são corrompidas ou degradadas quando transformadas em mercadoria. Desse modo, para decidir emque circunstância o mercado faz sentido e quais aquelas em que deveria ser mantido a distância, temos de decidir que valor atribuir ao bens em questão - saúde, educação, vida familiar, natureza, arte, deveres cívicos e assim por diante. São questões de ordem moral e política, e não apenas econômicas. Para resolvêlas, precisamos debater caso a caso, o significado moral desses bens e sua correta valorização.

Destarte, o professor de ciência política da Universidade de Harvard propõe que nem todos os bens podem ser comprados e vendidos, devendo haver um limite estabelecido caso a caso, tendo em vista sempre a objeção da equanimidade e corrupção.

\section{VIDA PARA CONSUMO}

Zygmunt Bauman, renomado sociólogo polonês, descreve a transformação das pessoas em mercadorias. Essa mudança é analisada através da transição de uma sociedade de produtores para uma sociedade de consumidores. Nessa nova organização social, as pessoas são promotoras das mercadorias e as próprias mercadorias a serem promovidas. Explica Bauman (2008, p. 20, grifo no original):

Na maioria das descrições, o mundo formado e sustentado pela sociedade de consumidores fica claramente dividido entre as coisas a serem consumidas e os que as escolhem; as mercadorias e seus consumidores: as coisas a serem consumidas e os seres humanos que as consomem. Contudo, a sociedade de consumidores é o que é precisamente por não ser nada desse tipo. O que a separa de outras espécies de sociedade é exatamente o embaçamento e, em última instância, a eliminação das divisões citadas acima. Na sociedade de consumidores, ninguém pode se tornar sujeito sem primeiro virar mercadoria, e ninguém pode manter segura sua subjetividade sem reanimar, ressuscitar e recarregar de maneira perpétua as capacidades esperadas e exigidas de uma mercadoria vendável. 
Interessante o paralelo traçado entre a sociedade de produtores e sociedade de consumidores. Na primeira, a ideia da venda da capacidade de trabalho surge para justificar o mercado de trabalho, afinal o homem não poderia ser um simples objeto posto à venda. A partir do momento em que se separa a capacidade de trabalho da pessoa que realiza o trabalho, aquele encontra uma fundamentação razoável: a capacidade de trabalho pode ser uma mercadoria, o homem jamais. É o que os economista denominaram de fetichismo da mercadoria. Na sociedade de consumidores, é a subjetividade que tem a função de separar a pessoa da mercadoria. A proposição cartesiana que se divide entre sujeito (consumidor) e objeto (mercadoria), evita qualquer tentativa de objetificação do ser humano - sujeito por excelência. Assim, "[s]e foi destino do fetichismo da mercadoria ocultar das vistas a substância demasiado humana da sociedade de produtores, é papel do fetichismo da subjetividade ocultar a realidade demasiado comodificada da sociedade de consumidores" (BAUMAN, 2008, p. 23, grifo no original).

A grande ruptura se deu, segundo Zygmunt Bauman, na passagem do consumo ao consumismo. O consumo é um atributo dos indivíduos (consome-se energia, alimentos etc.), ao passo que o consumismo representa um atributo da sociedade. $\mathrm{O}$ consumismo vem ocupar o lugar que o trabalho ocupou no modelo anterior de sociedade. Essa sociedade de consumo é pautada sob uma cultura "agorista" e imediatista, em que sempre surgem novos desejos e necessidades que devem ser saciadas imediatamente. É nessa perspectiva que o sociólogo polonês fala em um tempo pontilhista, marcado por rupturas e descontinuidades. Cada ponto é marcado por "instantes eternos", representando um mar de possibilidades. Aqui, ao contrário do tempo linear, não há espaço para progresso, para futuro - o momento é o agora. O valor supremo e característico da sociedade de consumidores seria uma vida feliz, uma felicidade terrena, instantânea e perpétua. E é justamente por essa cultura hedonista, alcançada pelo consumo, que a infelicidade é apontada como uma abominação.

Outra característica dessa sociedade de consumidores é a crescente individualização do ser humano, gerada pelo enfraquecimento e fragmentação dos vínculos humanos. A preocupação e a solidariedade com o outro faz com que cresça a relação de dependência, de responsabilidade, de alteridade. O indivíduo consumidor, marcado pelo hedonismo imediatista, não faz planos, não cria laços - o consumo é uma atividade solitária.

O indivíduo da sociedade de consumidores é também a própria mercadoria. Esse indivíduo não nasce pronto, mas deve fazer de si mesmo (e não apenas tornar-se) uma mercadoria vendável. 
Trata-se de um processo de auto fabricação em que o próprio mercado fornece as ferramentas necessárias. É nesse processo de objetificação do ser humano que as barreiras entre sujeito e objeto se entrelaçam. A grande questão é, portanto, se todos os aspectos da existência humana podem se tornar objetos de consumo. Dessa maneira, características tuteladas por direitos da personalidade também estariam abarcadas por esse processo de mercantilização? Pela perspectiva apontada pelo sociólogo polonês, sim.

A história da humanidade é descrita, de maneira geral, como um caminhar rumo a um ganho de liberdade pessoal e racionalidade. Zygmunt Bauman (2007, p. 82) pondera a respeito de uma outra possível perspectiva:

Em vez de ser um passo rumo à emancipação final do indivíduo em relação às múltiplas coerções externas, essa passagem pode se revelar como a conquista, a anexação e a colonização da vida pelo mercado de bens de consumo - sendo o significado mais profundo (ainda que reprimido e escondido) dessa conquis ta a elevação das leis escritas e não escritas do mercado à categoria de preceitos da vida; o tipo de preceito que só pode ser ignorado por conta e risco de quem quebra a norma, e que tende a ser punido com a exclusão.

Essa colonização do mundo da vida pelo mercado acaba por fazer do Estado (enfraquecido e solapado) um dos grandes prejudicados. A soberania, característica fundamental do Estado moderno, passa a ser estabelecida pelo mercado de consumo. É esse que estabelece os incluídos e excluídos pela regra do jogo. Esse "estranho soberano" é ávido por autopromoção, apresenta suas sentenças e não admite apelação. Assim, tal como apontado por Stefano Rodotà, o mercado se apresenta como uma alternativa nada democrática. O domínio do Estado pelo mercado também ocorre pela própria delegação de funções e prerrogativas.

A questão central parece ter sido resumida por James Livingstone (apud BAUMAN, 2007, p. 152): "a forma mercadoria penetra e transforma dimensões da vida social até então isentas da sua lógica, até o ponto em que a própria subjetividade se torna uma mercadoria a ser comprada e vendida no mercado, como a beleza, a limpeza, a sinceridade e a autonomia”. Destarte, a conclusão aponta na direção da transformação das pessoas em mercadorias. $O$ ponto a indagar seria: existe um limite para transformação? Todos aspectos da vida humana são bens de consumo? Qual o papel do direito frente a esse novo modelo de sociedade que se apresenta? São perguntas sem respostas - ao menos por enquanto. O grande mérito de Bauman reside na identificação desse novo modelo de sociedade. 


\section{CONCLUSÃO}

Um jurista italiano, um filósofo americano, um sociólogo polonês. Partindo de perspectivas e métodos distintos, todos chegaram a apontamentos similares. Primeiro o diagnóstico: vivemos em uma sociedade de consumo (ou somos uma sociedade de consumo) em que quase todos (ou todos) os aspectos da vida humana, patrimoniais ou existenciais, foram abarcados pela esfera do mercado - e o direito não escapa dessa nova visão de mundo. As soluções caminham para a mesma direção. Para Stefano Rodotà, o mercado dos direitos acaba com a liberdade e a dignidade das pessoas, não podendo ser tutelado pela ordem jurídica. Direitos fundamentais representam um duplo limite, por um lado aos indivíduos, por outro ao Estado. Não é possível comprar e vender direitos da personalidade como se fossem um bem jurídico qualquer, são inegociáveis. Michael Sandel entende que o mercado não deve tomar conta de tudo, havendo limites morais a serem respeitados. A equanimidade e a corrupção são barreiras que devem ser observadas, casuisticamente, frente à atuação do mercado. Assim, conclui que nem tudo pode ser comprado e vendido. Zygmunt Bauman, por sua vez, aponta a transformação das pessoas em mercadorias. Observa que o mercado chegou ao ponto em que a própria subjetividade se tornou um bem que pode ser comprado e vendido. Desse modo, a pessoa se torna promotora da mercadoria e também a mercadoria que promove.

Afinal, seriam os direitos da personalidade mercadorias? Na visão dos autores estudados, os direitos da personalidade são entendidos e tratados como mercadorias na sociedade contemporânea, contudo não deveriam ser. O mercado tem tomado proporções inimagináveis, tomando posse de áreas que deveria se abster.

Frente à construção teórica desses importantes pensadores, levanta-se uma terceira hipótese, situada entre as duas mencionadas no início desse artigo. Direitos da personalidade, direitos existenciais, direitos fundamentais devem ser deixados em uma esfera alheia ao mercado, todavia, esta norma pode ser descontruída na análise do caso concreto.

Explica-se. As duas primeiras hipóteses aventadas não admitem exceções - ou os direitos da personalidade podem se tornar mercadorias, ou não podem. Não obstante, o novo paradigma de Direito (pós-positivismo jurídico) e de Estado (Estado Democrático de Direito) não contempla respostas fáceis, prontas, acabadas. A nova hermenêutica indica um pensar a partir do caso, a partir do problema. Mas se é assim, por que não levantar uma outra hipótese, no sentido de não haver um 
limite pré-concebido? Primeiro, em razão da historicidade dos direitos da personalidade. A construção desses direitos não está sendo realizada agora, mas vem sendo edificada ao longo de uma tradição jurídica. Uma mudança dessa maneira poderia ser por demais abrupta. Segundo, porque, como bem apontado por Rodotà, os direitos da personalidade não são apenas direitos individuais, mas também direitos "dos outros". Desse modo, é mister lembrar que esses direitos estão inseridos em uma sociedade, em um contexto de alteridade. Terceiro, em razão da segurança jurídica. Parece contraditório se falar em um novo paradigma de direito e de hermenêutica e mencionar a segurança jurídica, típica do pensamento positivista-modernista. Contudo, a segurança jurídica tem sua importância no paradigma hodierno. Se, repentinamente, tudo pode ser comercializado, uma situação de insegurança extrema poderia surgir. Por fim, pode se falar em argumentos pragmáticos. Seria o sistema jurídico, em especial o judiciário, capaz de atender demandas dessa complexidade em grandes quantidades? Um juiz Hércules demanda tempo, poderes e estruturas à sua altura - afinal Hércules realizou apenas doze trabalhos.

Ao longo do artigo foram apresentadas diversas situações em que direitos existenciais aparecem em uma esfera de mercado. Também foram levantadas ao menos quatro hipóteses para os problemas apontados. Entende-se um exagero que todos os casos se estabeleçam sobre um mesmo limite rígido e instransponível. Assim, a fixação de uma norma que possa ser desconstruída casuisticamente, configurou-se como uma hipótese mais adequada para o problema proposto frente ao paradigma que se apresenta. Contudo, trata-se de uma hipótese que, como todas, deverá ser comprovada ou refutada.

\section{REFERÊNCIAS}

ALEXY, Robert. Teoria dos Direitos Fundamentais. Tradução Virgílio Afonso da Silva. 2. ed. São Paulo: Malheiros Editores, 2012.

BAUMAN, Zygmunt. Vida para consumo: a tranformação das pessoas emmercadoria. Rio de Janeiro: Zahar, 2008.

COISAS belas e sujas. Reino Unido: Imagem Filmes, 2003. 97 min.

GOMES, Orlando. Introdução ao direito civil. 10. ed. Rio de Janeiro: Forense, 1992.

MAÑAS, José Luis Piñar. Prólogo. In: La vida y las reglas:entre el derecho y el no derecho. Madrid: Editorial Trotta, 2010. 
PEREIRA, Caio Mário da Silva. Instituições de Direito Civil. Volume I. Rio de Janeiro:

Forense, 2007.

PERLINGIERI, Pietro. Perfis do direito civil: introdução ao Direito Civil Constitucional. Tradução de Maria Cristina De Cicco. 3 ed. Rio de Janeiro: Renovar, 2002.

SANDEL, Michael. O que o dinheiro não compra: os limites morais do mercado. Rio de Janeiro: Civilização Brasileira, 2014.

SCHREIBER, Anderson. Direitos da Personalidade. 2. ed. São Paulo: Editora Atlas, 2013.

RODOTÀ, Stefano. La vida y las reglas: entre el derecho y el no derecho. Madrid: Editorial Trotta, 2010.

SÁ, Maria de Fátima Freire de; NAVES, Bruno Torquato de Oliveira. Manual de Biodireito. Belo Horizonte: Del Rey, 2011.

SÁ, Maria de Fátima Freire de; MOUREIRA, Diogo Luna. Os novos rumos da reprodução humana: turismo reprodutivo e aspectos polêmicos das técnicas de reprodução. In press. 2015

STANCIOLI, Brunello. Renúncia ao exercício de direitos da personalidade. Belo Horizonte: Del Rey, 2010.

SWISSINFO. Governo suíço quer restringir "turismo da morte". Disponível em: $<$ http://www.swis sinfo.ch/por/governo-su\%C3\% AD\%C3\% A7o-quer-restringir--turismo-damorte-/893172> Acesso em 6 ago. 2015. 